"This is the peer reviewed version of the following article: [Petrovska, K., Sheehan, A. and Homer, C. S.E. (2017), Media Representations of Breech Birth: A Prospective Analysis of Web-Based News Reports. Journal of Midwifery \& Women's Health, 62: 434-441.

doi:10.1111/jmwh.12609.], which has been published in final form at [doi: 0.1002/hec.3276] This article may be used for non-commercial purposes in accordance with Wiley Terms and Conditions for Self-Archiving." 


\title{
Media representations of breech birth: A prospective analysis of Web-based news reports
}

\author{
Karolina Petrovska ${ }^{1}$, Athena Sheehan ${ }^{2}$, Caroline SE Homer ${ }^{1}$, \\ ${ }^{1}$ Centre for Midwifery, Child and Family Health, Faculty of Health, University of Technology Sydney, \\ Level 7, 235 Jones St, Ultimo NSW 2007 (PO Box 123) University of Technology Sydney, Australia. \\ ${ }^{2}$ School of Nursing and Midwifery, Western Sydney University, Sydney, NSW Australia
}

\begin{abstract}
Introduction

Recent research has demonstrated that the media presentation of childbirth is highly medicalized, often portraying birth as risky and dramatic. Media representation of breech presentation and birth is unexplored in this context. This study aimed to explore the content and tone of news media reports relating to breech presentation and breech birth.
\end{abstract}

\section{Methods}

Google alerts were created using the terms "breech" and "breech birth" in online Englishlanguage news sites over a 3-year period from $1 / 1 / 2013$ to $31 / 12 / 2015$. Alerts were received daily and filed for analysis and data were analyzed to generate themes.

\section{Results}

A total of 138 web based news reports were gathered from 9 countries. 5 themes that arose from the data included: The problem of breech presentation; The high drama of vaginal breech birth; The safe option of cesarean birth versus dangers of vaginal breech birth; The defiant mother versus the saintly mother; and Vaginal breech birth and medical misadventure.

\section{Discussion}

Media reports in this study predominantly demonstrated negative views towards breech presentation and vaginal breech birth. Cesarean birth was portrayed as the safe option for breech birth, while vaginal breech birth was associated with poor outcomes. Media presentations may impact decision-making about mode of birth for pregnant women with a breech fetus. Health care providers can play an important role in balancing the media depiction 
of planned vaginal breech birth by providing non-judgmental, evidence-based information to such women to facilitate informed decision-making for birth.

Key words: Breech birth, media, content analysis, women's decision-making. 


\section{PRECIS}

This study found Web based news reports take a largely negative view of vaginal breech birth which may influence women's decision-making for this birth option.

\section{QUICK POINTS}

- The media often portrays childbirth as a risky and dramatic event requiring medical intervention.

- This study explored media representation of breech presentation and birth.

- The results of this study observed that the 3 years of Web based news reports collected for this research took a largely negative view of vaginal breech birth, while cesarean section was seen as a safe, predictable option for breech birth.

- Some women may wish to explore the option of vaginal breech birth and the media's treatment of vaginal breech birth may impact on their decision-making process

- The role of the clinicians is crucial in providing balanced and non-judgmental. information that is essential for women to be able to make informed decisions about their options breech birth. 


\section{INTRODUCTION}

The media plays a significant role in both creating and influencing cultural norms and social discourse..$^{1-3}$ The media's ability to shape public opinion by setting health agendas has also been shown to create accepted truths, irrespective of evidence that may exist to the contrary, which members of society may use to inform their own narratives and decision-making. ${ }^{3,4}$ The internet, a relatively new form of media, enables the public to have instant access to information that has been shown to shape social views and consumer health choices, ${ }^{3}$ with "Dr. Google" being a term commonly heard in health care lexicon today.

Researchers have used media content analysis as a systematic approach to explore how the media reports and represents childbirth..$^{5-7}$ This approach seeks to interrogate media content to uncover deeper meaning of texts to audiences, to understand the likely interpretations of the audience, and to see how language and visual imagery combine to create meaning around childbirth. Results from recent research show the media perpetuates the medicalization of childbirth, often portraying it as risky and dramatic, with portrayals of normal birth often being under-represented. .5

An unexplored area in this field is media portrayal of breech presentation and breech birth. Breech presentations occur in 3-5\% of pregnancies, with most of these fetuses in high income countries being currently born by elective cesarean birth. ${ }^{9-11}$ Data on the percentage of women with a breech fetus who seek planned vaginal breech birth are limited, however, the American College of Obstetricians and Gynecologists notes in its committee opinion "During the past decade, there has been an increasing trend in the United States to perform cesarean delivery for term singleton fetuses in a breech presentation. "12

US data from 2002 demonstrates the rate of cesarean birth for women in labor with breech presentation was $86.9 \% .{ }^{13}$ The remaining $13.1 \%$ of vaginal breech births included both planned and unplanned vaginal breech births, suggesting the figures for planned vaginal breech births are much fewer. In Australia, where some of the news reports in this study were sourced, 2014 data show that of the 13,519 fetuses who were breech at term ( $4.3 \%$ of fetuses), $87 \%$ were born by caesarean. This demonstrates an increase in caesarean birth for breech foetuses from 
$77 \%$ in $1995 .{ }^{14}$ No statistical data are available on the number of planned vaginal breech births in Australia. The United Kingdom, which was also a source country for data collected in this study, also has no recent national data available on the incidence of planned vaginal breech birth.

The small number of breech fetuses born vaginally can be partially attributed to a large international trial published in 2000, known as the Term Breech Trial, ${ }^{15}$ which concluded that cesarean birth was the safest way for fetuses in the breech presentation to be born. The results of the study showed that perinatal mortality, neonatal mortality, or serious neonatal morbidity was significantly lower for the planned Cesarean birth group than for the planned vaginal birth group (17 of 1039 [1.6\%] vs 52 of 1039 [5.0\%]). The Trial's findings also demonstrated that there were no differences between groups in terms of maternal mortality or serious maternal morbidity (41 of 1041 [3.9\%] vs 33 of 1042 [3.2\%]). ${ }^{15,16}$ More recent research and systematic reviews reinforcing the Trial's results have since been released, ${ }^{17,18}$ with one study noting that vaginal breech birth carries a 2 to 5 fold greater relative risk of short term morbidity and mortality than cesarean birth. ${ }^{11}$

Following the Term Breech Trial, studies of maternal and neonatal outcomes of Trial participants were conducted to gauge the longer term impact of mode of birth. The findings demonstrated planned cesarean birth was not associated with a reduction in risk of death or neurodevelopmental delay in children at 2 years of age (14 children [3.1\%] vs 13 children [2.8\%]). ${ }^{19}$ There was no also no difference in maternal outcomes at 2 years postpartum for planned Cesarean birth and planned vaginal birth for the singleton breech fetus at term; in breast feeding, relationship with child or partner, pain, subsequent pregnancy, incontinence, depression, urinary, menstrual or sexual problems, fatigue, or distressing memories of the birth experience. ${ }^{20}$ Despite this, the Trial's findings have been enthusiastically embraced by maternity facilities in the Western world. ${ }^{21}$ Cesarean births for breech fetuses have increased since 2000 , and the number of clinicians skilled in facilitating vaginal breech births has decreased significantly. ${ }^{10,11}$

Evidence supporting vaginal breech birth is based on a number of studies demonstrating safety of vaginal breech birth for carefully selected women who have appropriate care and care provider expertise. ${ }^{10,11,21-24}$ A recent meta-analysis indicated that the absolute risk of vaginal 
breech birth is lower than previously thought. In this study, Berhan et al concluded that the absolute risks of perinatal mortality, fetal neurologic morbidity, birth trauma, 5-minute Apgar score less than 7 and neonatal asphyxia in the planned vaginal birth group were $0.3,0.7,0.7$, 2.4 , and $3.3 \%$, respectively. ${ }^{11}$ Long-term childhood outcomes of breech presentation by intended mode of birth have also demonstrated that planned vaginal breech birth confers no additional risks for child health, development, or educational achievement compared to planned Cesarean birth. ${ }^{25}$

Despite significant bodies of research and clinical guidelines from professional colleges supporting the option of vaginal breech birth for carefully selected women, such as those from Canada, Australia and the United States, vaginal breech birth continues to remain rare across the world. ${ }^{10-12,21-23,26,27}$ The option of vaginal breech birth also remains controversial due to research conducted since the Term Breech Trial citing significant flaws in the design and recommendations of the Trial. ${ }^{21,28,29}$

A small number of facilities internationally continue to offer the option of planned vaginal breech birth, supported by skilled clinicians working in specialised services. ${ }^{10,23,24,30}$ However, these services are in the minority and, as a result, women who are diagnosed with a breech fetus late in pregnancy have very few options but to have a cesarean birth. Some women continue to seek the option of planned vaginal breech birth and source care providers to support them in their birth choices, however this has proven to be challenging. ${ }^{31-33}$

Socio-cultural attitudes towards breech birth have been shown to impact on women's decision- making for vaginal breech birth. ${ }^{27}$ Given the media plays a role in influencing these attitudes, $^{1-3}$ we were interested in the media exposure that women who have a breech fetus late in pregnancy might be subjected to and the content and tone of any media or news reports relating to breech presentation and birth, as no studies exist that have explored this issue.

\section{METHODS}

\section{Design}

A qualitative descriptive study using media content analysis was undertaken. Media content analysis takes a systematic approach to studying media by objectively identifying specified 
characteristics within text. ${ }^{2}$ Data were sourced from information on the internet that took the form of news reports.

Google alerts were created to search for the term "breech" and "breech birth" on the internet over a 3 year period from 1 January 2013 to 31 December 15 . Alerts were received on a daily basis by the first author and filed throughout this period for analysis at the end of the data gathering period. Google was used as it facilitates gathering data that can be tailored to the specific needs of the researcher. Each of the news reports received during the 3 year period was accessed, read and saved. Sampling was limited to reports from media outlets reporting on all aspects relating to breech presentation and breech birth. Internet chat forums and personal blogs were excluded. Reports that discussed the same news story were counted for the purposes of gathering information from different journalists and countries. Reports were checked to ensure they were written by different authors and not a republication of the same story using similar language. Those that reports that had the same author were only counted once.

While Google permits collection of data on a daily basis to a nominated email address, which in this study was the first author, cross-checking also took place. Another search engine, Yahoo, was used to cross check data collected to ensure a comprehensive collection of data was undertaken, as has been undertaken in similar research. ${ }^{4,7}$

\section{Data Analysis}

The media content analysis used inductive category development to interrogate the language to develop themes and better understand how social language constructs messages about breech presentation and breech birth. Inductive analysis involves working from specific observations of categories and patterns (e.g. issues or messages) to a broad theory or conclusion. ${ }^{2}$ Immersion in the data involved reading and re-reading each news story multiple times to ascertain messages portrayed through the language and images used. This method aimed to uncover how the reader could potentially be persuaded by the language and/or images used to create meaning. This approach to media content analysis is said to bring a 
systematic approach to qualitative text analysis by matching pre-existing category to a text, rather than matching the text to a category. ${ }^{2}$

The pre-existing categories were based on work done by Jeffries (2007) in her analysis of how the female body is portrayed in the media. Jeffries suggests that language in the media plays a significant role in the construction of socio-cultural views. ${ }^{34}$ Jeffries uses a number of defined analytical techniques to analyze media content, which have been adapted for use in this study (Table 1).

\section{<Insert Table 1: Analysis techniques used for news reports on breech presentation and birth here>}

To further support this analysis, key text elements for review of the language in the media were also used to explore the tone or tenor of the reports, such as the use of adjectives that give an indication of a writer's attitude, tonal qualities such as aggressiveness or emotional language and identification of pronouns as key signifiers of meaning in text. ${ }^{2}$ Research ethical approval was not sought as the data from the internet being studied are in the public domain and fully accessible. ${ }^{4,35,36}$

A second and third researcher critiqued the first researcher's findings and themes to reduce the potential for bias and increase the credibility of the research. ${ }^{4}$ This process facilitates lead researcher reflexivity by permitting reflection and acknowledgement of any bias or personal beliefs. ${ }^{37}$

\section{RESULTS}

A total of 138 web-based news reports were gathered over a 3 year period from $1 / 1 / 13$ to $31 / 12 / 15$ and analyzed. Reports came from a variety of countries, including the United States (60\%), United Kingdom (17\%), Australia (14\%), Canada (4\%), New Zealand (3\%), Germany (3\%), India (1\%), Singapore (1\%) and Kenya (1\%).

The alerts were sourced from a variety of media, such as online newspapers, videos from televised news reports and online magazines. All categories that appeared in the 'news' portion of the Google alert were included. This covered a wide variety of news sources, such as 
local and national newspapers as well as 'lighter' news sources for more targeted audiences such as entertainment news sites.

Of the 138 news reports that were collected, 17 (12\%) were reported the option of vaginal breech birth as a legitimate choice for women. The remainder portrayed breech presentation and breech birth negatively. The data were analysed to generate themes, with a total of 5 themes generated. Table 2 describes how themes were generated from each analysis technique by providing example quotes from the sample source (Table 2).

\section{<Insert Table 2: Audit trail of analysis techniques used here>}

\section{The "Problem" Of Breech Presentation}

Diagnosis of breech presentation in pregnancy was portrayed as a problem in the news reports collected for this study, with descriptions in the majority of the data (69\%) of the fetus being the "wrong way" and "upside down" and "in a dangerous position".

A total of 55 headlines (39\%) described breech as a pregnancy complication for high profile celebrity Kim Kardashian, who discovered her fetus was breech late in her second pregnancy. All reports were investigated for this study as they were sourced from different media outlets that may have treated the reporting of this story differently. One report was noted to use language that implied breech presentation is to be feared. An external cephalic version eventually turned the fetus to a cephalic presentation, with the "problem" of breech presentation being corrected and the fetus being turned to the "right position": the star said 'it feels so good to not have the stress of thinking I need a C-section.

Another celebrity, Amber Rose, also had a fetus in the presentation late in pregnancy. Entertainment news sites spoke of her plans for a homebirth "unravelling", with Rose frantically trying to encourage the fetus to turn: ...her efforts were futile and Rose eventually accepted the reality that she would have to undergo a c-section.

By contrast, planned vaginal breech birth was mentioned less often ( $12 \%$ of all news reports), with the accepted view being that a fetus does not turn antenatally, cesarean birth is inevitable. 


\section{The "High Dram"' And "Rarity" Of Vaginal Breech Birth}

Breech birth was most often reported as being unplanned and dramatic. Descriptions of panic and danger during an unplanned breech birth occurred in $19 \%$ of reports, with alarming language such a "chaotic" and "horrific" being used to illustrate the scene of a vaginal breech birth.

$7(5 \%)$ of the news reports gathered described the involvement of emergency personal, either via telephone or in person, which added to the drama of newborns making a "dramatic debut". The outcomes of these births were portrayed as "beating the odds" with the portrayal that luck was involved in avoiding imminent death of the newborn:

...it was the second baby that would prove more difficult for Adam [a paramedic] to deliver. The second born was breech... when the baby came out he was blue and not breathing regularly...it required a lot of tactile stimulation to get him breathing again. "After the job you start to think about what could've gone wrong and you start to go, 'that was a close one.'"

Vaginal breech birth was also spoken of in miraculous tones, with medical staff being noted as rarely witnessing vaginal breech birth and women gaining "superhero powers" and achieving the impossible when giving birth to a breech newborn vaginally.

\section{The Safe Option Of Cesarean Birth Versus The Dangers Of Vaginal Breech Birth} Cesarean birth was viewed by the majority of the reports (69\%) as the superior and lifesaving option for management of breech birth. News reports that viewed vaginal breech birth as negative did not discuss the risks associated with cesarean birth or evidence supporting the safety of vaginal breech birth. In 17 (12\%) of the reports, quotes that were included from doctors appeared to add weight and professional authority to the opinions reflected in the reports, with one doctor stating that cesarean birth was the best choice for breech birth as vaginal birth could "kill the infant." 
Descriptions of the potential complications relating to vaginal breech birth were listed extensively, without mention of the risk of cesarean birth. Emotive language was also used, for example:

The dangers of breech birth are numerous, including taking a longer time, exerting too much strain on the pelvis and injury to the birth canal which can lead to severe bleeding and painful urination. The greater threat is on the baby who can be distressed as a result of deprivation of oxygen leading to brain damage or cerebral palsy. An injury can also occur to any of their tiny limbs

News reports supportive of vaginal breech birth were limited (12\%). These articles provided a balanced view of risks and benefits for both vaginal breech birth and cesarean birth, noting that cesarean birth does not necessarily provide a safe or predictable outcome and that women should understand all options for care before making an informed decision. These reports were more equivocal about the risks and benefits of all options available, and discussed the need for individualized decision-making for women so they can choose the best plan for themselves and their newborn.

Woman's choice was discussed in only 9 out of the 138 articles (7\%) and the prevailing view was that medical opinion should lead the decision-making process for birth. The dominant tone was one of medical authority and a "doctor-knows-best" approach.

\section{The defiant mother versus the saintly mother}

The number of news reports describing women seeking the option of vaginal breech birth were limited ( $8 \%$ of all data gathered), however the language in these reports portrayed these women as difficult and demanding. They were described as defiant and resistant to medical advice. By contrast, women who changed their original birth plan (vaginal birth) and agreed to a cesarean birth were seen as self-sacrificing and "doing the right thing" for the perceived safety of their newborn. One report provided a more nuanced approach between the selfish and the saintly mother. This report expressed was more neutral in relation to the option of vaginal breech birth: 
Morena's [an American actress] decision to have a vaginal breech birth has prompted both praise and criticism, with some charging that she put her ideal "birth experience" above what was best for the baby, while others have applauded her for following her instincts and pursuing the birth she wanted

This theme demonstrates that the negative perceptions around the safety of planned vaginal breech birth impacted on how the mother was perceived with regard to her choices for birth.

\section{Vaginal Breech Birth and Medical Misadventure}

Out of the 138 news reports collected, a proportion (16\%) reported lawsuits against health services and medical practitioners who were involved in vaginal breech births that resulted in adverse outcomes. Vaginal breech birth was described as an uncommon practice, with 2 of these births being planned vaginal breech births, while the remainder were unplanned births. All reports noted the inexperience of the clinician involved in the birth. For example, one report headlined "Fatal Breech Birth" noted:

The registrar [doctor training as a specialist] responsible for the delivery had only delivered 2 breech babies previously and the latter moments of the delivery had been 'panicked' and a 'mad fumble'

Headlines such as \$25.6 million malpractice lawsuit over vaginal delivery of breech baby imply that vaginal breech birth is associated with poor outcomes that bring high financial cost to the health facility or death of the neonate. Reports of misadventure associated with the alternative (cesarean birth) were not present in the data gathered.

3 news items reporting about lawsuits against health services and medical practitioners who were involved in vaginal breech births discussed the skill of the clinician attending the birth being a key factor in minimizing risks and poor outcomes for vaginal breech birth and that it may be a safe option for women who fulfill selected criteria. Despite this, the dominant view in the data gathered perceived the option of vaginal breech birth as increasing the likelihood of poor outcomes and increasing subsequent vulnerability to litigation for health services and medical practitioners. 


\section{DISCUSSION}

This study observed that 3 years of web-based news reports presented a largely negative view of vaginal breech birth. Breech presentation was viewed as a problem in the news reports, with stories predominantly covering unplanned breech birth with a focus on the urgency and drama of the birth. Cesarean birth was seen as a safe, predictable option for breech birth in the data gathered.

The overall tone of the reports identified for this study was negative and alarming. The limited number of news reports supporting planned vaginal breech birth reinforces current perspectives that exist in dominant medical discourse that view vaginal breech birth unfavorably. ${ }^{33}$ Both Davis-Floyd and Founds note the strength of the medical system in informing social discourse around birth practices, which includes the popular media. ${ }^{38-40}$ The medical system's influence on social discourse is demonstrated in much of the literature studying media's treatment of birth in general, as well as choices for other modes of birth such as vaginal birth after cesarean birth. ${ }^{41-44}$ It appears the news reports investigated in this study have been influenced by the medical system's uptake of the findings of the Term Breech Trial, where Cesarean births are largely seen as the default management for breech presenting fetuses, and the risks associated with vaginal breech birth are perceived to be higher than current evidence suggests. ${ }^{11}$ The lack of detail regarding medical malpractice suits associated with vaginal breech birth demonstrate that the news reports examined in this study tended to focus on poor outcomes related to vaginal breech birth without deeper investigation of the possible causes of the adverse events. For example, there was little information regarding the presence, or absence, of skilled clinicians at these births, which is a key factor in maximizing safe outcomes for relating to vaginal breech birth. ${ }^{10,22,24}$ The exclusion of discussion regarding poor outcomes relating to cesarean birth and evidence supporting the safety of planned vaginal breech birth under specific conditions in the data collected reinforces a biased view in favor of cesarean birth. ${ }^{10,11,22,23,45}$ Additionally, the data collected included reports on unplanned vaginal breech births that involved the attendance of emergency personnel. This is likely to add to the perception of vaginal breech birth as an emergency and that breech presentation itself is therefore problematic. 
The predominance of focus on negative outcomes in the reports in this study may be explained by media theory which suggests that the media's role is to satisfy the audience's need to seek health-promoting information as a part of risk profiling at fateful moments and to assist the audience in warning of potential dangers by focusing on "things that can go wrong". ${ }^{3}$ Audiences may also seek emotional stimulation through dramatization that has an entertaining effect-fear and anxiety, for example, may be heightened so that the audience is experiencing these feelings as a contrast to security and pleasure. In this study, vaginal breech birth and the risks and dangers associated with it contrasted with the perceived safety and security of cesarean birth.

Medical technology, and its ability to provide a "predictable outcome", can be seen to reinforce cultural rituals and an acceptance that medical intervention is superior to nature. ${ }^{38,46,47}$ Media text analyzed in this study portrayed the need for intervention (ie, cesarean birth) to overcome the perceived danger associated with vaginal breech birth. ${ }^{5,8}$ This has the potential to lead the audience to believe that cesarean births are the only option to "manage" or avert the risks for the woman and her breech fetus.

The inter-relationship between the media and medical discourse has also contributed to the socially accepted perception that women's reproduction is intimately intertwined with medical technology. ${ }^{5,47}$ This has created a normalization of technology, thereby creating pressure on women to accept the status quo of cesarean birth for management of breech birth $^{31}$. Rather than demonstrate a balanced view of the risks and benefits of all options for birth, portrayal of planned vaginal breech birth in the reports collected for this study can be seen as a way of controlling the bodies of women during birth to guarantee a perceived good outcome. $^{8}$

Women who seek or who have had a vaginal breech birth were depicted as difficult and defiant in the reports examined for this study. These women display a trust in the birthing process that challenges the idea that birth is an imperfect and untrustworthy process that should be managed with technology. ${ }^{48}$ The dominant norm portrayed in the data collected was that a woman's wish for a natural birth was secondary to her newborn's safety, and that "good mothers" are self-sacrificing and women who challenge the norm are vilified by the 
media. 5,47,49-51 This study reinforces this view - women who insisted on trying for a vaginal breech birth were seen less favorably than those women who sacrificed their desired birth plan for the "safety" of their newborn.

The majority of the reports collected for this analysis did not clearly articulate evidence for all options for breech birth. The treatment of this option for birth in the data collected provides an example of how media reporting may demonstrate a bias towards cesarean birth for breech presentation and this may have an impact on women's decision-making for breech birth. The role of the clinicians is crucial in providing balanced and non-judgmental information that is essential for women to support informed decisions about their options for birth when diagnosed with a breech fetus. 9,33,52-54 This may be challenging in the current climate where cesarean birth is seen by many maternity facilities across the world as the safer, default option for birth of a breech fetus. However, the value of woman-centred care should be a fundamental element of maternity care, and for this to truly be achieved, the woman should be supported in her decision-making for birth. ${ }^{55}$ The provision of evidence-based information for all birth options plays a significant role in this process.

This study had several limitations. The inclusion of English language websites may have excluded data from countries that have increased support for the option of vaginal breech birth, such as Scandinavian countries or the Netherlands. The dominance of data from the United States may have also impacted on conclusions drawn from the analysis. This study was limited to written text only and did not include radio interviews or television video clips as these mediums are not comprehensively available on the internet. The use of Google as the sole search engine may have also created limitations, of which the authors are unaware, in the level of comprehensiveness of the data gathered.

\section{CONCLUSION}

Media reports in this study predominantly demonstrated negative views towards breech presentation and vaginal breech birth. Perceptions of vaginal breech birth in the news reports collected for this study reinforced dominant medical views regarding current practices for management of breech presentations. Cesarean birth was portrayed as the safe option for birth, while vaginal breech birth is viewed as a risk-laden choice that inevitably ended in poor 
outcomes. This portrayal may impact on women's decision-making for birth when diagnosed with a breech fetus during pregnancy. A significant role a health care provider can play in balancing the media depiction of vaginal breech birth is to provide non-judgmental, evidencebased information to women to facilitate informed decision-making for birth. 


\section{$\underline{\text { References }}$}

1. Ferguson SJ, Kasper AS. Breast cancer : society shapes an epidemic. 2002.

2. Macnamara J. Media content analysis: uses benefits \& bestpractice methodology. Asia Pacific Public Relations Journal. 2005;6(1):34.

3. Seale C. Health and media: an overview. Sociology of Health \& IIIness. 2003;25(6):513-531.

4. Dahlen HG, Homer CSE. 'Motherbirth or childbirth'? A prospective analysis of vaginal birth after caesarean blogs. Midwifery. 2// 2011;29(2):167-173.

5. Morris T, Mclnerney K. Media Representations of Pregnancy and Childbirth: An Analysis of Reality Television Programs in the United States. Birth. 2010;37(2):134-140.

6. Shaw RL, Giles DC. Motherhood on ice? A media framing analysis of older mothers in the UK news. Psychology \& Health. 2009/02/01 2009;24(2):221-236.

7. Dahlen HG, Homer CSE. Web-based News Reports on Midwives Compared with Obstetricians: A Prospective Analysis. Birth. 2012;39(1):48-56.

8. Luce A, Cash M, Hundley V, Cheyne H, van Teijlingen E, Angell C. "Is it realistic?" the portrayal of pregnancy and childbirth in the media. BMC Pregnancy and Childbirth. 2016;16(1):1-10.

9. Guittier M-J, Bonnet J, Jarabo G, Boulvain M, Irion O, Hudelson P. Breech presentation and choice of mode of childbirth: A qualitative study of women's experiences. Midwifery. 12// 2011;27(6):e208-e213.

10. Kotaska A, Menticoglou S, Gagnon R, et al. SOGC clinical practice guideline: Vaginal delivery of breech presentation: no. 226, June 2009. International journal of gynaecology and obstetrics: the official organ of the International Federation of Gynaecology and Obstetrics. Nov 2009;107(2):169-176.

11. Berhan $Y$, Haileamlak $A$. The risks of planned vaginal breech delivery versus planned caesarean section for term breech birth: a meta-analysis including observational studies. BJOG: An International Journal of Obstetrics \& Gynaecology. 2016;123(1):49-57.

12. ACOG. Mode of term singleton breech delivery. ACOG Committee Opinion No. 340. . Obstetrics and gynecology. 2006;108:235-237.

13. Martin J, Hamilton B, Sutton P. Birth: Final data for 2003. National Vital statistic reports. 2003;54.

14. (AlHW) AloHaW. Australia's mothers and babies 2014-in brief. Perinatal statistics series no. 32.: Canberra: AlHW.; 2016.

15. Hannah ME, Hannah WJ, Hewson SA, Hodnett ED, Saigal S, Willan AR. Planned caesarean section versus planned vaginal birth for breech presentation at term: a randomised multicentre trial. The Lancet. 10/21/ 2000;356(9239):1375-1383.

16. Su M, McLeod L, Ross S, et al. Factors associated with maternal morbidity in the Term Breech Trial. J Obstet Gynaecol Can. Apr 2007;29(4):324-330.

17. Vlemmix F, Bergenhenegouwen L, Schaaf JM, et al. Term breech deliveries in the Netherlands: did the increased cesarean rate affect neonatal outcome? A population-based cohort study. Acta Obstetricia et Gynecologica Scandinavica. 2014;93(9):888-896.

18. Hofmeyr GJ, Hannah M, Lawrie TA. Planned caesarean section for term breech delivery. Cochrane Database of Systematic Reviews. 2015(7).

19. Whyte $\mathrm{H}$, Hannah ME, Saigal $\mathrm{S}$, et al. Outcomes of children at 2 years after planned cesarean birth versus planned vaginal birth for breech presentation at term: The international randomized Term Breech Trial. American Journal of Obstetrics and Gynecology. 9// 2004;191(3):864-871. 
20. Hannah ME, Whyte $H$, Hannah WJ, et al. Maternal outcomes at 2 years after planned cesarean section versus planned vaginal birth for breech presentation at term: The international randomized Term Breech Trial. American Journal of Obstetrics and Gynecology. 9// 2004;191(3):917-927.

21. Lawson GW. The Term Breech Trial Ten Years On: Primum Non Nocere? Birth. 2012;39(1):3-9.

22. Glezerman M. Planned vaginal breech delivery: current status and the need to reconsider. Expert Review of Obstetrics \& Gynecology. Mar 2012 2012;7(2):159-166.

23. Goffinet $F$, Carayol M, Foidart JM, et al. Is planned vaginal delivery for breech presentation at term still an option? Results of an observational prospective survey in France and Belgium.

American Journal of Obstetrics \& Gynecology. 2006;194(4):1002-1011.

24. Borbolla Foster A, Bagust A, Bisits A, Holland $M$, Welsh A. Lessons to be learnt in managing the breech presentation at term: An 11-year single-centre retrospective study. Australian and New Zealand Journal of Obstetrics and Gynaecology. 2014;54(4):333-339.

25. Bin YS, Ford JB, Nicholl MC, Roberts CL. Long-term childhood outcomes of breech presentation by intended mode of delivery: a population record linkage study. Acta Obstetricia et Gynecologica Scandinavica. 2016:n/a-n/a.

26. RCOG. The management of breech presentation. 2006.

27. RANZCOG. C-Obs 11: Management fo Breech Presentation at Term. Melbourne: RANZCOG;2013.

28. Glezerman M. Five years to the term breech trial: The rise and fall of a randomized controlled trial. American Journal of Obstetrics and Gynecology. 1// 2006;194(1):20-25.

29. Kotaska A. Inappropriate use of randomized trails to evaluate complex phenomena: Case study of vaginal breech delivery. British Medical Journal. Vol 3292004:1039+.

30. Catling C, Petrovska K, Watts N, Bisits A, Homer CS. Barriers and facilitators for vaginal breech births in Australia: Clinician's experiences. Women Birth. Oct 12 2016;29:138-143.

31. Petrovska K, Watts N, Sheehan A, Bisits A, Homer C. How do social discourses of risk impact on women's choices for vaginal breech birth? A qualitative study of women's experiences. Health, Risk \& Society. 2016:1-19.

32. Petrovska K, Watts NP, Catling C, Bisits A, Homer CSE. 'Stress, anger, fear and injustice': An international qualitative survey of women's experiences planning a vaginal breech birth. Midwifery. 1// 2017;44:41-47.

33. Homer CSE, Watts N, Petrovska K, Sjostedt C, Bisits A. Women's experiences of planning a vaginal breech birth in Australia. BMC Pregnancy and Childbirth. 2015;15(1):89.

34. Jeffries L. Textual construction of the female body: A critical discourse approach. New York: Palgrave Macmillan. ; 2007.

35. Betts D, Dahlen HG, Smith CA. A search for hope and understanding: An analysis of threatened miscarriage internet forums. Midwifery. 6// 2014;30(6):650-656.

36. Peddie VL, Whitelaw N, Cumming GP, Bhattacharya S, Black M. Qualitative website analysis of information on birth after caesarean section. BMC Pregnancy and Childbirth. 2015;15:180.

37. Steen M, Roberts T. The Handbook of Midwifery Research. . Oxford.: Wiley-Blackwell; 2011.

38. Davis-Floyd R. Birth as an American rite of passage. University of California Press; 2003.

39. Roth $\mathrm{H}$, Homer C, Fenwick J. "Bouncing back": How Australia's leading women's magazines portray the postpartum 'body'. Women and birth : journal of the Australian College of Midwives. 2012;25(3):128-134.

40. Founds SA. Women's and providers' experiences of breech presentation in Jamaica: A qualitative study. International Journal of Nursing Studies. 11// 2007;44(8):1391-1399.

41. Munro S, Kornelsen J, Hutton E. Decision making in patient-initiated elective cesarean delivery: the influence of birth stories. Journal of midwifery \& women's health. Sep-Oct 2009;54(5):373379. 
42. Fenwick J, Staff L, Gamble J, Creedy DK, Bayes S. Why do women request caesarean section in a normal, healthy first pregnancy? Midwifery. 8// 2010;26(4):394-400.

43. Mackenzie Bryers $\mathrm{H}$, van Teijlingen $\mathrm{E}$. Risk, theory, social and medical models: A critical analysis of the concept of risk in maternity care. Midwifery. 10// 2010;26(5):488-496.

44. Malacrida C, Boulton T. The best laid plans? Women's choices, expectations and experiences in childbirth. Health:. January 1, 2014 2014;18(1):41-59.

45. Alcorn KL, O'Donovan A, Patrick JC, Creedy D, Devilly GJ. A prospective longitudinal study of the prevalence of post-traumatic stress disorder resulting from childbirth events. Psychological Medicine. Nov 2010 2010;40(11):1849-1859.

46. Tully KP, Ball HL. Misrecognition of need: Women's experiences of and explanations for undergoing cesarean delivery. Social Science \& Medicine. 5// 2013;85(0):103-111.

47. Coxon K, Scamell M, Alaszewski A. Risk, pregnancy and childbirth: What do we currently know and what do we need to know? An editorial. Health, Risk \& Society. 2012/09/01 2012;14(6):503510.

48. Leao MR, Riesco ML, Schneck CA, Angelo M. [Reflections on the excessive rates of cesareans in Brazil and the empowerment of women]. Ciencia \& saude coletiva. Aug 2013;18(8):2395-2400.

49. Charles S, Shivas T. Mothers in the media: Blamed and celebrated - an examination of drug abuse and multiple births. Pediatric Nursing. Mar/AprMar/Apr 2002 2002;28(2):142-145.

50. Weaver JJ, Statham H, Richards M. Are There "Unnecessary" Cesarean Sections? Perceptions of Women and Obstetricians About Cesarean Sections for Nonclinical Indications. Birth. 2007;34(1):32-41.

51. Johnston D, Swanson D. Invisible Mothers: A Content Analysis of Motherhood Ideologies and Myths in Magazines. Sex Roles. 2003/07/01 2003;49(1-2):21-33.

52. Kotaska A. IN THE LITERATURE:Combating Coercion: Breech Birth, Parturient Choice, and the Evolution of Evidence-Based Maternity Care. Birth. 2007;34(2):176-180.

53. Powell R, Walker S, Barrett A. Informed consent to breech birth in New Zealand. The New Zealand Medical Journal (Online). 2015 Jul 24 2015;128(1418):85-92.

54. Petrovska K, Sheehan A, Homer CSE. The fact and the fiction: A prospective study of internet forum discussions on vaginal breech birth. Women and Birth.

55. Dahlen HG. The politicisation of risk. Midwifery. 7// 2016;38:6-8. 
Table 1: Analysis techniques used for news reports on breech presentation and birth

\begin{tabular}{|c|c|}
\hline Category & Description \\
\hline Naming & $\begin{array}{l}\text { Initially, the language in the text was scrutinized to assess the presence } \\
\text { of a word or words that were used as a label to describe breech } \\
\text { presentation in a negative or positive light. Jeffries }{ }^{34} \text { notes the highly } \\
\text { repetitive nature of "naming" terms sends strong ideological messages } \\
\text { and thus has the potential to influence readers' perceptions. }\end{array}$ \\
\hline Describing & $\begin{array}{l}\text { "Describing" examined how the presence of a breech fetus, or the } \\
\text { event of a breech birth, was portrayed and how the news story was } \\
\text { constructed based on depictions of breech presentation and birth. }\end{array}$ \\
\hline Contrasting & $\begin{array}{l}\text { "Contrasting" focused on identifying the construction of opposites and } \\
\text { the language used when the writer of the news story created opposing } \\
\text { scenarios of 'good' versus 'bad'. }\end{array}$ \\
\hline $\begin{array}{l}\text { Enumerating and } \\
\text { Exemplifying }\end{array}$ & $\begin{array}{l}\text { "Enumerating" and "exemplifying" is the next technique aiming at } \\
\text { identifying generic categories through the constructions of 'lists' of } \\
\text { descriptions that exemplified breech presentation or birth in either a } \\
\text { positive or negative light. }\end{array}$ \\
\hline $\begin{array}{l}\text { Assuming and } \\
\text { Implying }\end{array}$ & $\begin{array}{l}\text { The final technique seeks to uncover hidden meanings in the text that } \\
\text { implies a message to the reader at a subconscious level. Previous } \\
\text { research has suggested that when similar messages are repeatedly } \\
\text { delivered, they act as a reinforcement of ideological assumptions and } \\
\text { conceptual influences that the reader is vulnerable to }{ }^{34,39} \text {. }\end{array}$ \\
\hline
\end{tabular}


Table 2: Audit trail of analysis techniques used

\begin{tabular}{|c|c|c|}
\hline $\begin{array}{l}\text { Analysis } \\
\text { technique } \\
\text { category }\end{array}$ & Theme & Example from sample source \\
\hline Naming & $\begin{array}{l}\text { The 'problem' of } \\
\text { breech } \\
\text { presentation }\end{array}$ & $\begin{array}{l}\text { Their fetus was facing the } \\
\text { wrong way } \\
\text { Just last week she announced } \\
\text { her son was incorrectly } \\
\text { positioned in her womb, but } \\
\text { with the help of doctors, her } \\
\text { fears of subjecting the child to } \\
\text { a breech birth have been } \\
\text { alleviated. }\end{array}$ \\
\hline Describing & $\begin{array}{l}\text { The 'high drama' } \\
\text { and 'rarity' of } \\
\text { vaginal breech } \\
\text { birth }\end{array}$ & $\begin{array}{l}\text { The clock is ticking once birth } \\
\text { begins" } \\
\text { It was a natural breech-so } \\
\text { rare, even some of the } \\
\text { medical staff had not seen } \\
\text { one before. }\end{array}$ \\
\hline $\begin{array}{l}\text { Contrasting; } \\
\text { Enumerating and } \\
\text { exemplifying }\end{array}$ & $\begin{array}{l}\text { The safe option of } \\
\text { cesarean birth vs } \\
\text { the dangers of } \\
\text { vaginal breech } \\
\text { birth }\end{array}$ & $\begin{array}{l}\text { C-section is still the best } \\
\text { choice for a breech baby, } \\
\text { since vaginal delivery could } \\
\text { kill the infant. } \\
\text { C-section is still the best } \\
\text { choice for a breech baby, } \\
\text { since vaginal delivery could }\end{array}$ \\
\hline
\end{tabular}




\begin{tabular}{|c|c|c|}
\hline & & $\begin{array}{l}\text { kill the infant. Cesarean } \\
\text { section is the safest mode of } \\
\text { delivery for the breech } \\
\text { presenting baby at term and } \\
\text { that should be discussed with } \\
\text { the mother. }\end{array}$ \\
\hline Contrasting & $\begin{array}{l}\text { The defiant } \\
\text { mother vs the } \\
\text { saintly mother }\end{array}$ & $\begin{array}{l}\text { She will defy doctor's advice } \\
\text { that her breech baby should } \\
\text { be delivered by cesarean } \\
\text { section. }\end{array}$ \\
\hline $\begin{array}{l}\text { Assuming and } \\
\text { implying }\end{array}$ & $\begin{array}{l}\text { Vaginal breech } \\
\text { birth and medical } \\
\text { misadventure }\end{array}$ & $\begin{array}{l}\text { \$25.6 million malpractice } \\
\text { lawsuit over vaginal delivery } \\
\text { of breech baby }\end{array}$ \\
\hline
\end{tabular}

